\title{
Energy Distribution Analysis of Multiple Injectors for the Double Compression Expansion Engine (DCEE) Concept
}

\begin{abstract}
The present study shows the impact of multiple injectors with distinctive spray and injection angles on the engine efficiency, heat transfer, and exhaust losses. It is well known from previous studies that multiple injectors, particularly two-injectors, improve the air-fuel mixing while simultaneously reducing the heat transfer losses by keeping hot reaction zones away from the combustion cylinder walls. However, it is unclear how the spray-to-spray, umbrella, and spray-orientation angles would impact the overall energy distribution in both the combustion cylinder and double compression expansion engine (DCEE) concept. In this study, three-dimensional (3-D) Reynold-averaged Navier-Stokes (RANS) simulations were conducted in a heavy-duty single-cylinder engine, comparing three-injectors and two different side-injectors cases with a baseline case of centrally mounted single-injector. To obtain the baseline case and validate the computational fluid dynamics (CFD) data, the engine was operated at 1200 rpm, and the fuel mean effective pressure (FuelMEP) of 40 bar using conventional diesel fuel was fixed. One-dimensional (1-D) simulations then utilized the CFD-based in-cylinder pressure and rate of heat release (RoHR) traces to analyse the energy distribution of the DCEE concept. The CFD results show that the three-injectors and the best side-injectors case lead to $1.2 \%$-points and $0.2 \%$-points improvement of gross indicated efficiency and heat losses reduction of $1.3 \%$-points and $2 \%$-points, respectively, compared to the baseline single-injector case. This is due to the longer injector-wall distance from the side-injections, thereby reducing the heat transfer losses, compared to the large coverage area of the high-temperature gases for the baseline case. The 1-D results show that a high brake thermal efficiency of 53\% and $52.7 \%$ can be achieved with the three-injectors and the best sideinjectors case, respectively, compared to $51.9 \%$ of the baseline case. This was due to the advanced combustion phasing, lower heat transfer losses, and higher conversion efficiency of exhaust losses from the combustion cylinder into useful work in the expansion cylinder of the DCEE concept, resulting in an overall higher engine efficiency for multiple injectors.
\end{abstract}

\section{Keywords}

Multiple injectors; Conventional diesel combustion (CDC); Double compression expansion engine (DCEE); Energy distribution

\section{Introduction}

Four-stroke combustion engines fuelled with gasoline and diesel fuels are presently dominating the ground transportation sector. This is attributed to the high specific energy density, engine efficiency, cost-effectiveness, and reliability advantages. The engine-exhaust emissions of nitrogen oxides $\left(\mathrm{NO}_{\mathrm{x}}\right)$ and particulate matter $(\mathrm{PM})$ have shown a drastic decline over the past decades [1]. However, with an increased emphasis on climate changes, the reduction of greenhouse gases $(\mathrm{GHG})$ needs substantial efforts to increase the engine efficiency and lower the carbon-dioxide $\left(\mathrm{CO}_{2}\right)$ emissions. Towards these goals, low-temperature combustion (LTC) concepts such as homogeneous charge compression ignition (HCCI) [2-5], partially premixed combustion (PPC) [6-10], and reactivity controlled compression ignition [11-13] have been extensively investigated. Through these low-temperature combustion concepts, the heat transfer losses can be reduced; however, the efficiencies associated with combustion, exhaust, gas exchange, and friction losses in a conventional four-stroke engine is still an outstanding issue which led to lower brake thermal efficiency (BTE).

Split-cycle or compound engine concepts were proposed to improve the thermodynamic efficiency by dividing the compression and expansion strokes of the four-stroke engine into multiple cylinders. These engine concepts include the diesel series XIV engine [14], the Scuderi [15], CryoPower engine [16], the compact compression ignition engine [17,18], and general motors compound engine [19]. The diesel series XIV engine had two combustion cylinders connected to an expansion cylinder, resulting in lower fuel consumption and heat losses through exhaust valves. The Scuderi engine concept with a compression and expansion cylinder showed a fast combustion rate and lower $\mathrm{NO}_{\mathrm{x}}$ emissions but with a penalty of engine efficiency [20]. The CryoPower engine concept composed of a compression and combustion cylinder showed a BTE of $60 \%$ but had a limited engine speed range [21]. The compact compression ignition engine concept consisted of intake, combustion, and exhaust cylinders, while the general motors compound engines had a compressor, power, and expander cylinders. While they claimed high efficiency, no published data is available to date.

One of the split-cycle concepts recently investigated is the double compression expansion engine (DCEE), which has achieved high thermodynamic efficiency by simultaneously reducing the exhaust and friction losses [22-24]. A 4-4 version of the DCEE concept is comprised of a large-size lowpressure (LP) cylinder, a small-size high-pressure (HP) cylinder, an LP tank with charge air cooler (CAC), and a cross-over channel, resulting in lower friction losses in LP cylinder, and reduced heat transfer losses in HP cylinder [22]. Due to the advent of both compression and expansion stages in the HP unit, over-expansion of exhaust gases was a concern. However, this issue was avoided using a 2-4-2 concept composed of a compression cylinder, 
a combustion cylinder, an expansion cylinder, an LP tank with CAC, and an HP tank [25]. Many previous studies using one-dimensional (1-D) simulations reported a high BTE of $50 \%$ or higher across a wide range of engine loads and the air-excess ratio [22,25,26].

The additional compression and expansion cylinders of the DCEE concept has the potential to reduce the compression ratio of the combustion cylinder, resulting in a smaller surface-area to volume ratio and therefore reduced heat transfer losses $[22,23,25]$. However, the DCEE concept also relies on a high effective compression/expansion ratio, i.e. for the compression and expansion cylinders to achieve high engine efficiency and therefore requires a high peak cylinder pressure (PCP) in the combustion cylinder, resulting in increased heat transfer losses. The latter effect is found to be more dominant than the former effect. To reduce the heat transfer losses while utilizing DCEE exhaust energy recovering capability, multiple injectors can be effectively utilized. Previous studies has demonstrated the benefits of lowered heat losses and reduced soot-NO $\mathrm{N}_{\mathrm{x}}$ emissions [27-29] with multiple injectors concept. For example, the heat losses could be reduced up to $2 \%$-points in a heavy-duty diesel engine based on the pistonbowl geometry and operating conditions $[30,31]$.

In this study, three-injectors and two side-injectors cases were investigated for spray-to-spray, umbrella, and spray-orientation angles using CFD simulations, and the results are compared to those of the central-mounted single-injector case. To provide a baseline case and validate the CFD results for conventional diesel combustion (CDC) using a single-injector, experiments were conducted in a single-cylinder heavy-duty engine at a middle-load condition. The in-cylinder pressure and rate of heat release (RoHR) traces obtained from the CFD simulations were consequently used as an input to the 1-D modeling of combustion cylinder and DCEE concept for the analysis of energy distribution.

\section{Methodology}

\subsection{Engine Experiments}

Figure 1 shows a schematic of the single-cylinder heavy-duty diesel engine used for the conventional diesel combustion (CDC) experiments. The engine has been modified from a conventional Volvo D13, 6-cylinder by deactivating five of the cylinders. A pneumatic pressure regulator was installed in the intake manifold to control the intake air pressure. The airflow rate and intake air temperature were measured using an air flowmeter (Bronkhorst) and air heater (Leister), respectively, as illustrated in Figure 1. A mixing tank in the intake manifold while an expansion tank in the exhaust manifold was placed to reduce the pressure fluctuations. As listed in Table 1, the engine has a displacement volume of $2130 \mathrm{~cm}^{3}$ with a bore, stroke, and connecting rod length of $131 \mathrm{~mm}, 158 \mathrm{~mm}$, and $255 \mathrm{~mm}$, respectively. A low geometric compression ratio of 11.5 was used such that the combustion cylinder heat transfer losses are minimized, as an efficiency benefit for the double compression expansion engine (DCEE) concept. A distributed pump common-rail fuel injection system (Delphi F2E) directly injects the diesel fuel through a non-pumping solenoid injector at 1500 bar injection pressure. The injector nozzle has seven holes with a nozzle hole diameter of $248 \mu \mathrm{m}$. The spray cone angle, umbrella angle and discharge coefficient of the nozzle were $10^{\circ}, 150^{\circ}$, and 0.94 , respectively. To measure the total injected fuel mass, a mass balance system was used. Several pressure sensors and thermocouples were installed at various locations of the intake and exhaust manifolds to monitor the localized pressures and temperatures continually. A LabVIEW FPGA-based real-time embedded system (NI CompactRIO 9038) was used to control and acquire the measured data. The crank angle signals of $0.2^{\circ} \mathrm{CA}$ resolution were received from a rotary encoder (Leine Linde) mounted on the crankshaft.

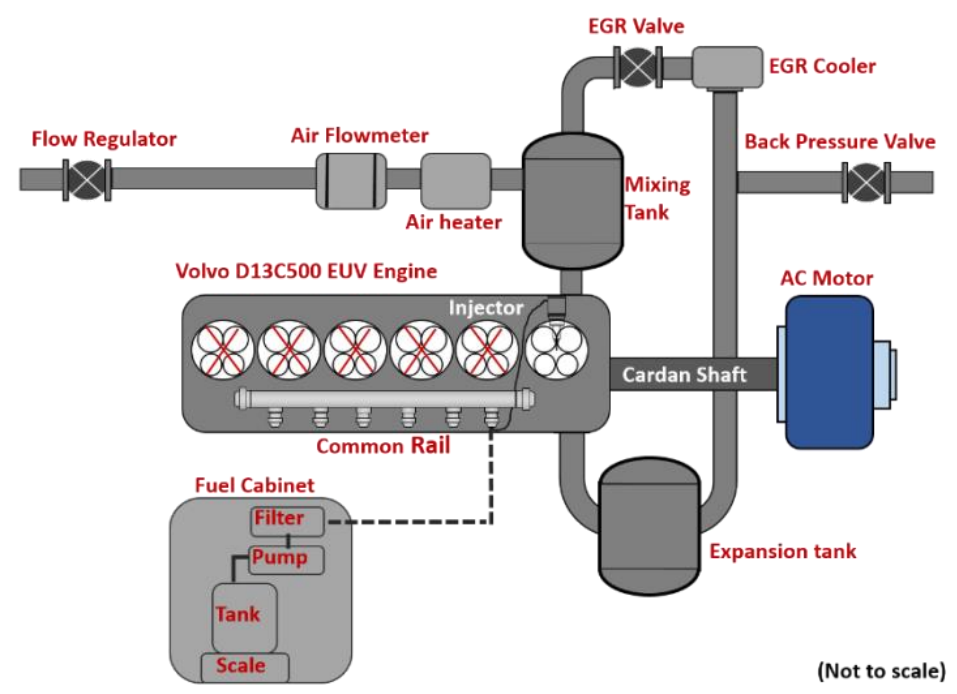

Figure 1. A schematic of the single-cylinder heavy-duty diesel engine setup.

The engine was coupled to an AC motor (ABB) for constant engine speed tests at 1200 revolutions per minute (rpm). The coolant was circulated through the cylinder head and liner and was maintained at a temperature of $\sim 85^{\circ} \mathrm{C}$ using a water pump, water heater, heat exchanger, and a control valve. The intake air temperature and the pressure were fixed at $\sim 65^{\circ} \mathrm{C}$ and 4 bar-absolute, respectively. The experiments were conducted using European diesel fuel of 53.8 cetane number. A conventional diesel combustion (CDC) mode was selected with a double injection strategy. A pilot injection/duration of $-5^{\circ} \mathrm{CA}$ aTDC/200 $\mu$ s was used to enhance the pre-combustion mixing and reduce the pressure rise rate, while a main

Page 2 of 17 
injection/duration of $-1{ }^{\circ} \mathrm{CA}$ aTDC/1500 $\mu$ s was used to control the combustion phasing, similar to our previous studies [32,33]. A typical middleload condition was selected with the total fuel injection mass of $\sim 189 \mathrm{mg} / \mathrm{cycle}$. Fuel mean effective pressure (FuelMEP), defined as the ratio of total input fuel energy to the cylinder displacement volume, was kept fixed at $40 \mathrm{bar}$.

The in-cylinder pressure was analyzed for 1000 consecutive cycles via a piezoelectric transducer (AVL GH15DK) and a charge amplifier (AVL FI PIEZO). Noting that the coefficient of variation $(\mathrm{CoV})$ of the indicated mean effective pressure (IMEP) was found to be $1.8 \%$, representing stable combustion.

Table 1. Engine specifications and operating conditions

\begin{tabular}{|l|l|}
\hline \multicolumn{2}{|c|}{ Engine specifications } \\
\hline Displacement volume (single cylinder) $\left[\mathrm{cm}^{3}\right]$ & 2130 \\
\hline Bore/Stroke $[\mathrm{mm}]$ & $131 / 158$ \\
\hline Connecting rod & 255 \\
\hline Compression ratio & $11.5: 1$ (geometric) \\
\hline Fuel injection system & Delphi F2E common-rail \\
\hline Number of injection holes & 7 \\
\hline Nozzle hole diameter $[\mu \mathrm{m}]$ & 248 \\
\hline Spray cone angle $\left[{ }^{\circ}\right]$ & 10 \\
\hline Spray umbrella angle $\left[{ }^{\circ}\right]$ & 150 \\
\hline Discharge coefficient & 0.94 \\
\hline & 1200 \\
\hline Engine speed $[\mathrm{rpm}]$ & $\sim 85$ \\
\hline Coolant temperature $\left[{ }^{\circ} \mathrm{C}\right]$ & $\sim 65$ \\
\hline Intake air temperature $\left[{ }^{\circ} \mathrm{C}\right]$ & 4 (absolute) \\
\hline Intake air pressure $[\mathrm{bar}]$ & Diesel \\
\hline Fuel & -5 (pilot), -1 (main) \\
\hline Injection timing $\left[{ }^{\circ} \mathrm{CA}\right.$ aTDC] & 200 (pilot), 1500 (main) \\
\hline Injection duration $[\mu \mathrm{s}]$ & 1500 \\
\hline Injection pressure $[\mathrm{bar}]$ & $\sim 189$ \\
\hline Injected fuel mass $[\mathrm{mg} / \mathrm{cycle}]$ & 40 \\
\hline FuelMEP $[$ bar] & \\
\hline
\end{tabular}

\subsection{CFD Simulations Setup}

The CONVERGE v3.0.12 software performed heavy-duty diesel engine simulations based on the renormalized group k-epsilon RANS turbulence model. All liquid-fuel thermo-physical properties followed the built-in diesel2 settings. The Kelvin-Helmholtz Rayleigh-Taylor (KH-RT) [34] model accounted for fuel injection and spray-breakup with 200,000 spherical parcels per injection. A Frossling droplet evaporation correlation [35] estimated the spherical diameters. The droplet size distribution followed the Rosin-Rammler cumulative probability distribution. Upon evaporation, the fuel was assumed n-heptane to simplify calculations.

The combustion was described by a reduced kinetic mechanism, containing 61 species and 270 reactions, developed for complex toluene primary reference fuels but useful for $n$-heptane simulations [36]. A SAGE combustion model [37] mapped the cells into equivalence ratio bins of 0.05 increments and temperature bins of $5 \mathrm{~K}$.

All cases used a base grid size of $2 \mathrm{~mm}$ in all directions followed by scaling in two steps, fixed embeddings and adaptive refinements. Fixed level 3 embeddings captured the near-nozzle flow while omitting the interior nozzle flow. Furthermore, fixed level 1 embeddings, at the computational boundaries, ensured alignment with the logarithmic part from the law of the wall. Based on velocity and temperature gradients, level 2 adaptive mesh refinements (AMR) improved the grid locally. The grid level follows equation 1 as:

$\frac{\text { Base grid size }[\mathrm{mm}]}{2^{n}}$

Where $\mathrm{n}$ corresponds to the refinement level. The law-of-the-wall temperature boundary condition calculated the near-wall behavior, along with an Angelberger convective heat transfer model [38] assuming constant boundary temperatures. 


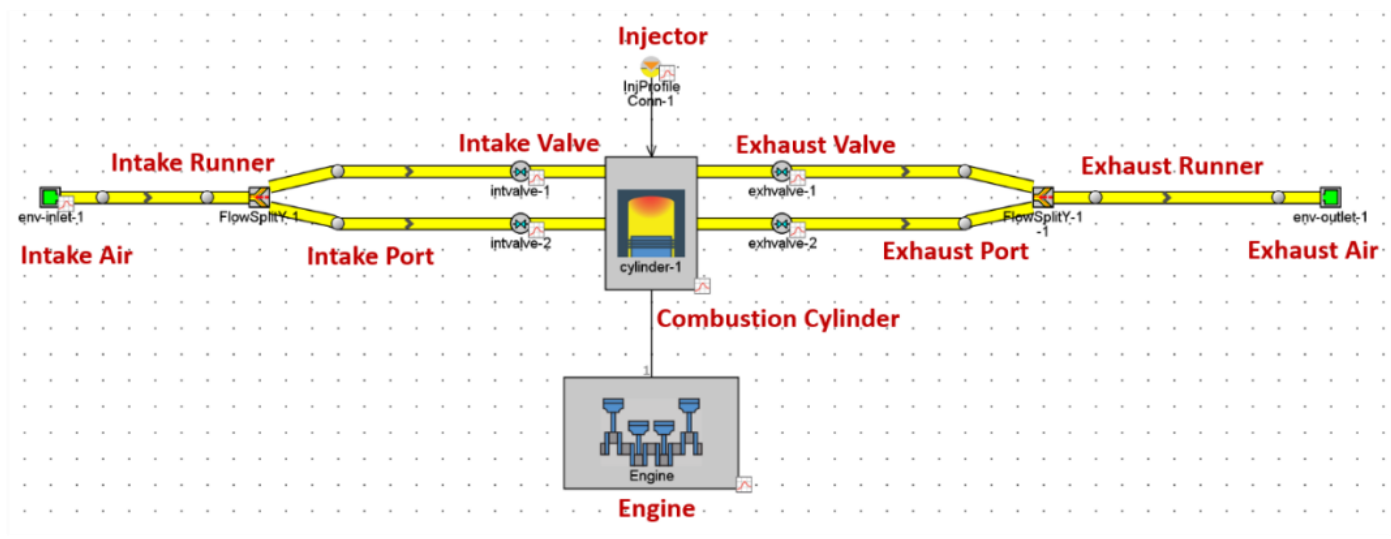

Figure 2. A modelling layout of the combustion cylinder using GT-Power.

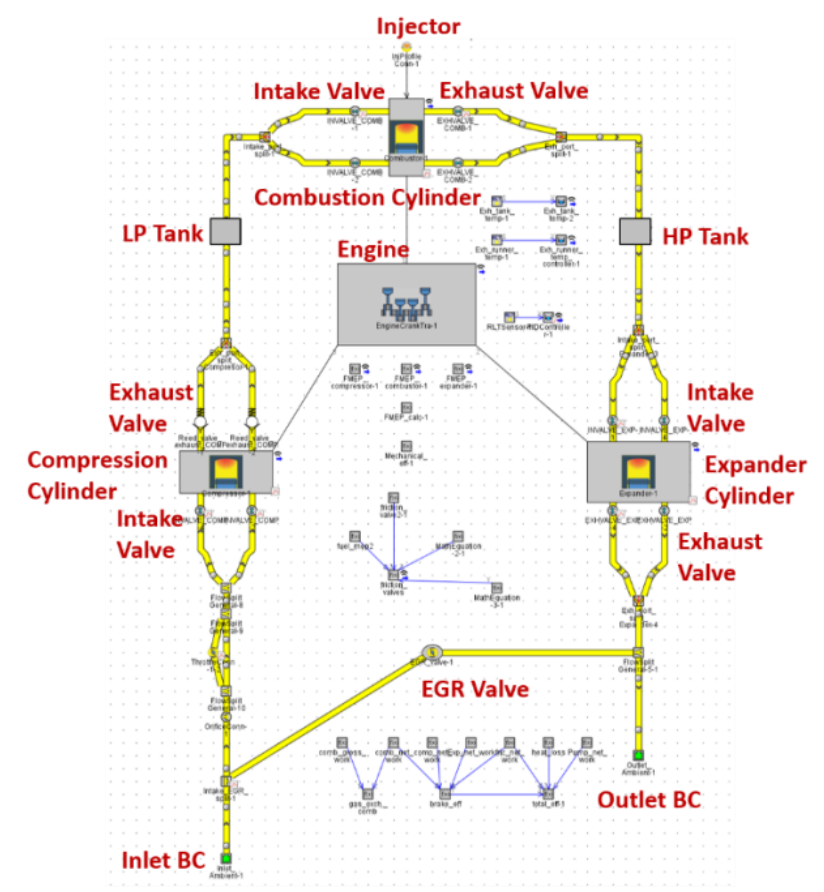

Figure 3. A modelling layout of the double compression expansion engine (DCEE) concept using GT-Power.

\subsection{GT-Power Simulation}

Based on the detailed 3D CFD simulation data, the performance assessment of the complete DCEE system was undertaken by a simplified 1-D modeling using the software GT-Power, v2019. The combustion cylinder was simulated with similar geometrical parameters as that of the experimental test cell, as shown in Table 1. The in-cylinder pressure and rate of heat release (RoHR) data were obtained from the CFD study, which was used as an input to the combustion cylinder model, as shown in Figure 2. A simplified combustion model was used to directly impose the burn rate profile as a function of crank angle degree. The calculated burn rate was analyzed from the CFD in-cylinder pressure data. For a given operating condition, the resultant incylinder pressure and heat release rate from this model was closely matched with that of the CFD data before feeding it to the main DCEE model.

The base model for the DCEE concept was developed by Volvo with 2-4-2 layout i.e., a 2-stroke compression cylinder, a 4-stroke combustion cylinder, and a 2-stroke expansion cylinder, as depicted in Figure 3. The displacement volume of the expansion cylinder is kept the largest compared to the compression and combustion cylinder. A large low-pressure (LP) and high-pressure (HP) tanks were installed before and after the combustion cylinder such that the isobaric gas exchange between the different cylinders is conducted, the pressure fluctuations is dampened, and allowing the nonsynchronized valve timings of the cylinders. The geometrical specifications for each of the cylinders and tanks are listed in Table 2 . The displacement volume and compression ratio of compression and expansion cylinders were selected based on trial-and-error tests to match the in-cylinder pressure, RoHR, inlet air pressure and temperature, and exhaust pressure of the combustion cylinder. The combustion cylinder's intake, exhaust valve timings, and valve lift profile were based on the test engine, whereas Volvo provided these parameters for the compression and expansion cylinders. It is 
important to highlight that all these geometrical parameters were selected based on the given experimental and CFD data. Different levels of peak cylinder pressures (PCPs) levels, inlet, and exhaust pressure, and intake and exhaust valve timings may impact the optimization results.

Table 2. Geometrical specifications for the DCEE model

\begin{tabular}{|l|l|l|}
\hline \multirow{4}{*}{$\begin{array}{l}\text { Displacement volume } \\
{[\text { liter }]}\end{array}$} & Compression cylinder & 2.81 \\
\cline { 2 - 3 } & Combustion cylinder & 2.13 \\
\cline { 2 - 3 } & Expansion cylinder & 5.82 \\
\cline { 2 - 3 } & Total & 10.76 \\
\cline { 2 - 3 } & LP tank & 32.4 \\
\cline { 2 - 3 } & HP tank & 32.4 \\
\hline Compression ratio & Compression cylinder & $15: 1$ \\
\cline { 2 - 3 } & Combustion cylinder & $11.5: 1$ \\
\cline { 2 - 3 } & Expansion cylinder & $15: 1$ \\
\hline
\end{tabular}

The in-cylinder convective heat transfer of the compression, combustion, and expansion cylinders were estimated using WoschniGT model, which closely imitates the classical Woschni correlation without considering the swirl effect [39]. For the combustion cylinder at each operating condition, the heat transfer coefficients were adjusted during intake, exhaust, compression, and exhaust strokes to replicate the heat transfer losses predicted using CFD study. For both the compression and expansion cylinders, the heat transfer coefficient was fixed at 1.0 due to experimental data's unavailability. It was also assumed that the combustion cylinder's inlet and the exhaust port are perfectly insulated, and therefore adiabatic wall temperature boundary condition was selected.

For predicting the overall friction losses of the DCEE concept, a linear friction model was used as [23-25]:

$$
\mathrm{FMEP}=\mathrm{PCP}(\mathrm{A} / \mathrm{B})
$$

FMEP is the friction mean effective pressure, PCP is the peak cylinder pressure, and the constants A and B were fixed at 1.2 and 200 . This was based on the assumption that FMEP is 1.2 bar at PCP of 200 bar. A detailed discussion of this model's selection can be found in the same work [23-25].

\subsection{CFD Models Validation}

Experimental data, coupled with a 1D-simulation during inlet valve closing (IVC), validated the CFD simulations for a single-injector case (see Figure 2). The 1D-simulation accounted for wall temperature and trapped gas composition, based on the experimental pressure trace. Table 3 presents these parameters where the combustion products, i.e., $\mathrm{CO}_{2}$ and $\mathrm{H}_{2} \mathrm{O}$ remain from the previous firing cycles.

Closed-volume cycle based CFD simulations were set in CONVERGE v3.0.12 during the valve closing period, i.e., from IVC to exhaust valve opening (EVO), to validate the numerical models against the experimental data. The model used the same engine geometrical parameters, as listed in Table 1, while the engine operating conditions for CFD simulations are presented in Table 3.

The validation process utilized three steps as follows: the first step involved effective compression ratio adjustments to match the motored pressure trace, followed by the introduction of in-cylinder trapped gases to match the fired pressure trace before the fuel injection event; the second step, where injection timing and duration were adjusted to account for the injector hydraulic delay (duration changed from $200 \mu \mathrm{s}$ to $208 \mu \mathrm{s}$ and $1500 \mu \mathrm{s}$ to 1508 $\mu \mathrm{s}$ ); the final step changed from an n-heptane to a diesel heating value to match the RoHR trace, while changing the CFD heat transfer models to match the experimental in-cylinder pressure trace.

Figure 4 compares CFD and experimental pressure, RoHR and temperature. The results match closely except for a second experimental RoHR peak. This peak follows from injector dribbling [40,41], which was not included in the CFD models. Table 4 further concludes well-matching CA10, CA50, CA90 and indicated efficiency values. The combustion cylinder energy distribution is further illustrated in Figure A1. 
Table 3. Operating conditions used for the CFD simulation setup

\begin{tabular}{|c|c|c|}
\hline \multirow{7}{*}{$\begin{array}{l}\text { Initial and boundary } \\
\text { conditions at IVC }\end{array}$} & In-cylinder pressure [bar] & 4.45 \\
\hline & In-cylinder temperature $\left[{ }^{\circ} \mathrm{C}\right]$ & 95 \\
\hline & Piston temperature $\left[{ }^{\circ} \mathrm{C}\right]$ & 277 \\
\hline & Liner temperature $\left[{ }^{\circ} \mathrm{C}\right]$ & 177 \\
\hline & Cylinder-head temperature $\left[{ }^{\circ} \mathrm{C}\right]$ & 277 \\
\hline & IVC $\left[{ }^{\circ} \mathrm{CA}\right.$ aTDC $]$ & -160 \\
\hline & EVO $\left[{ }^{\circ} \mathrm{CA}\right.$ aTDC $]$ & 140 \\
\hline \multirow{4}{*}{$\begin{array}{l}\text { Mass fractions of in- } \\
\text { cylinder gas composition } \\
\text { at IVC }\end{array}$} & $\mathrm{CO}_{2}$ & 0.0059 \\
\hline & $\mathrm{H}_{2} \mathrm{O}$ & 0.0021 \\
\hline & $\mathrm{N}_{2}$ & 0.7657 \\
\hline & $\mathrm{O}_{2}$ & 0.2263 \\
\hline \multirow[t]{4}{*}{ Injection parameters } & Injection timing $\left[{ }^{\circ} \mathrm{CA}\right.$ aTDC] & -5 (pilot), -1(main) \\
\hline & Injection duration $[\mu \mathrm{s}]$ & 208(pilot), 1520(main) \\
\hline & Fuel temperature $\left[{ }^{\circ} \mathrm{C}\right]$ & 90 \\
\hline & Injected fuel mass [mg/cycle] & 192 \\
\hline
\end{tabular}

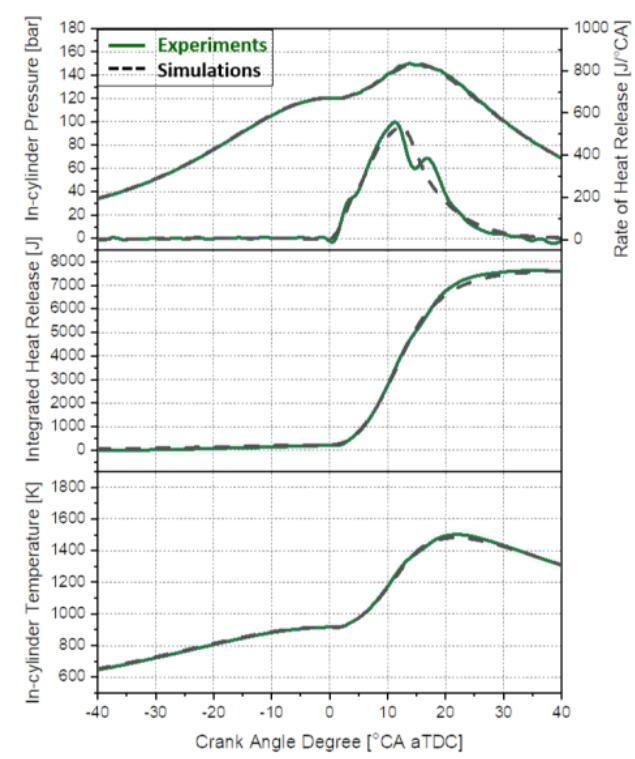

Figure 4. The CFD validation of the in-cylinder pressure, rate of heat release (RoHR), cumulative heat release and in-cylinder temperature using experimental data.

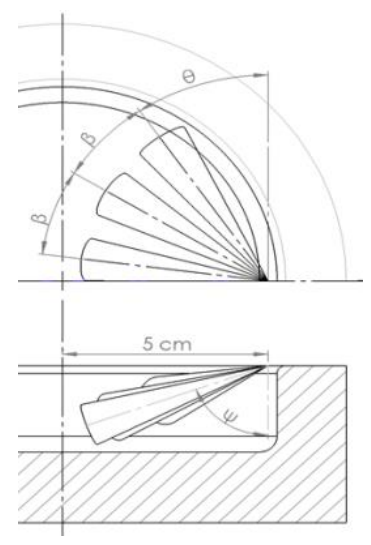

Figure 5. A schematic of side-injectors spray angles (at the top) and its location on the cylinder head (at the bottom). 


\begin{tabular}{|l|l|l|}
\hline & Experiments & CFD simulations \\
\hline CA10 [ ${ }^{\circ} \mathrm{CA}$ aTDC] & 4.8 & 4.9 \\
\hline CA50 [ ${ }^{\circ} \mathrm{CA}$ aTDC] & 12 & 12.3 \\
\hline CA90 [ ${ }^{\circ} \mathrm{CA}$ aTDC] & 20.8 & 23.1 \\
\hline Gross IMEP [bar] & 17.1 & 17.3 \\
\hline Gross Indicated Efficiency [\%] & 42.9 & 43.2 \\
\hline
\end{tabular}

\subsection{Design of Experiments}

This study aims to evaluate the feasibility of the multiple injectors and single-injector on the DCEE concept. The side-injectors spray angles were varied based on the following convention, as shown in Figure 5. Table 5 shows the angles sweep investigated in the present study. The cases are named by $\beta \mathrm{x} \psi \mathrm{x} \theta \mathrm{x}$, where $\mathrm{x}$ represents the corresponding angle value. Here, $\beta$ is the spray-to-spray angle, $\psi$ is the umbrella angle, and $\theta$ is the orientation angle. $\beta$ has been varied from 20 to $40, \psi$ has a value of either 70 or 80 , and $\theta$ has been varied from 110 to 150 and frontwards ( $\beta+\theta=180$ such that the center of the side injectors face towards the center of the combustion chamber). While $\psi$ for all three nozzles in the side injectors were set for constant value at either 70 or 80 for all other cases, a special case, denoted as $\psi=70,80,80$, was set with $\psi$ of the nozzle closest to the liner at 70 degrees, while $\psi=80$ for the other two nozzles. This case turned out to improve the performance by reducing the amount of fuel injected into the squish region. To investigate the impact of three injectors on the energy distribution, the best side injector case was performed together with the central injector. Previous studies highlighted the use of multiple injectors with swirl [42]. However, this study includes no swirl since the engine swirl ratio remains close to zero.

Table 5. Selected angular sweep parameters for the two- and three-injector cases

\begin{tabular}{|c|c|c|c|}
\hline Injectors & Beta $(\beta)[\operatorname{deg}]$ & 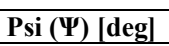 & Theta $(\theta)[\mathrm{deg}]$ \\
\hline \multirow{13}{*}{ Two-injectors (side) } & \multirow{6}{*}{20} & \multirow[t]{2}{*}{80} & 110 \\
\hline & & & 120 \\
\hline & & \multirow[t]{2}{*}{70} & 130 \\
\hline & & & 140 \\
\hline & & \multirow[t]{2}{*}{$70,80,80$} & 150 \\
\hline & & & Frontwards \\
\hline & \multirow[t]{4}{*}{30} & 80 & 110 \\
\hline & & 70 & 120 \\
\hline & & \multirow[t]{2}{*}{$70,80,80$} & 130 \\
\hline & & & Frontwards \\
\hline & \multirow{3}{*}{40} & 80 & \multirow{3}{*}{ Frontwards } \\
\hline & & 70 & \\
\hline & & $70,80,80$ & \\
\hline $\begin{array}{l}\text { Three-injectors } \\
\text { (central + side) }\end{array}$ & 20 & 80 & 150 \\
\hline
\end{tabular}
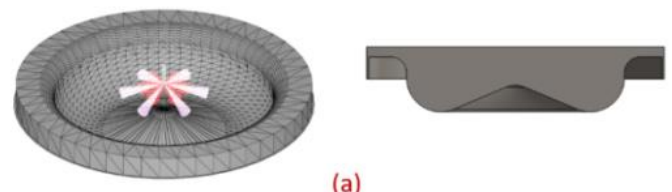

(a)
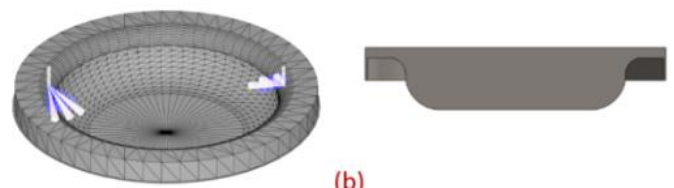

(b)
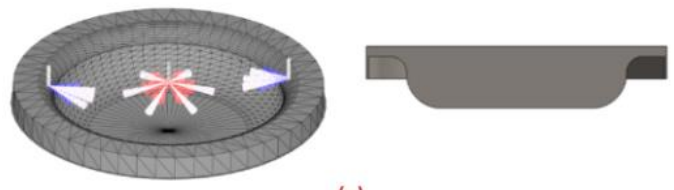

(c)

Figure 6. The injector and spray configuration of central injector with standard-bowl piston (a), side-injectors with flat-bowl piston (b), and threeinjectors with flat-bowl piston (c)

Page 7 of 17 
For the CFD simulations, it was assumed that the central injector has six holes compared to the three-holes for the side-injectors, allowing the same fuel flow rate for both cases. It was decided to consider an even number of total nozzle holes to execute a fair comparison between the three-injectors, two-injectors, and single-injector cases. For instance, the two side-injectors split the total fuel amount equally, i.e., $96 \mathrm{mg}$, and the three-injectors case injected $48 \mathrm{mg}$ from each side-injectors while $96 \mathrm{mg}$ from the central injector. The standard piston bowl shape presented in Figure 6(a) was used to evaluate conventional diesel combustion (CDC). Also, a flat piston geometry in Figure 6(b) and 6(c) were selected for side-injectors, and three-injectors cases since previous studies showed that the multiple injector concept is more effective with a flat piston-bowl [31,43]. All simulations in this study utilized the same fuel injection parameters, as shown in Table 3.

\section{Results and Discussion}

\subsection{CFD Analysis of the Combustion Chamber}

\subsubsection{Gross Indicated Efficiency}

Figure 7 presents the estimated gross indicated efficiency (GIE) for the top ten cases of the side-injectors and an optimized three-injectors case. It was found that only two out of all the test cases have shown an increase in GIE compared to the conventional diesel combustion (CDC), thereby demonstrating the importance of correct spray pattern and fuel allocation. Taking into account the results presented in Figure 7, only the top three cases, i.e., three-injectors, $\beta 20 \psi 80 \theta 150$, and CDC, and the lower GIE case, i.e., $\beta 20 \psi 70 \_80 \_80 \theta 140$ are considered for detailed investigations in the following sections.

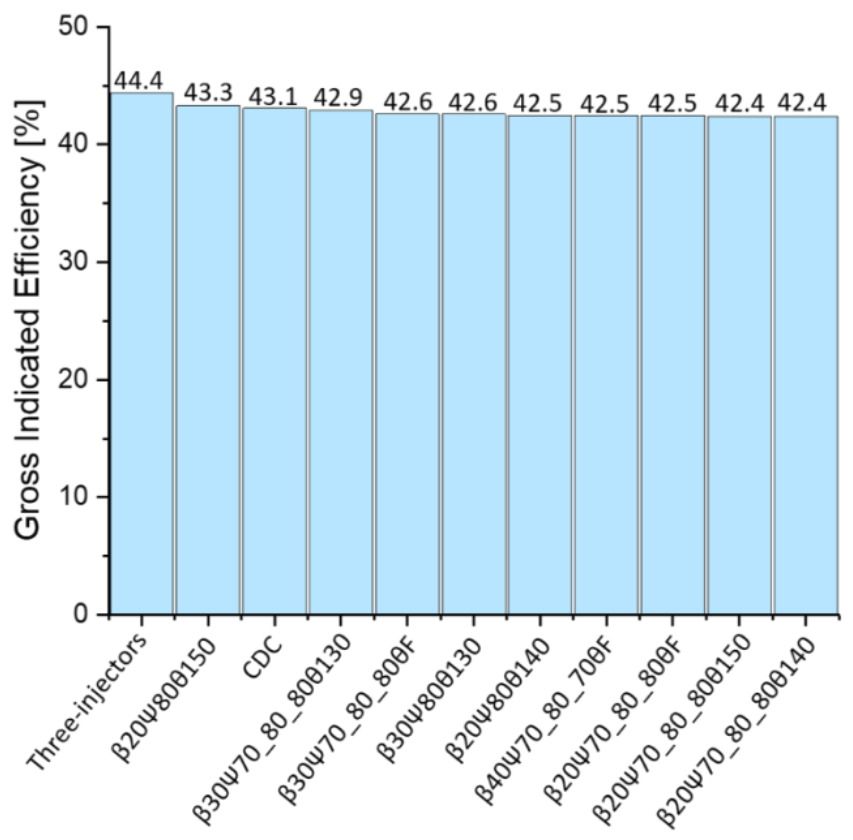

Figure 7. Gross indicated efficiency for all the studied cases.

\subsubsection{In-cylinder Pressure Analysis}

Figure 8 shows the in-cylinder pressure, rate of heat release (RoHR), and in-cylinder temperature traces for the top three cases and for the lowest GIE case, i.e., three-injectors (3I), $\beta 20 \Psi 80 \theta 150$ (2I-best), CDC, and $\beta 20 \Psi 70 \_80$ 800140 (2I-worst), respectively. The 2I and the 3I cases showed higher peak-pressure and peak-RoHR than the CDC case, indicating better air and fuel premixing. However, the pressure during expansion stroke for the 2Iworst case is found lower than the CDC case, leading to the detriment in gross IMEP. The 3I case compensates this behavior.

On the other hand, the 3I case shows an earlier peak of RoHR than the CDC case, resulting in a better centered thermodynamic cycle. This is also seen in Figure 9, where the 3I case shows an earlier combustion phasing (CA50) and faster combustion duration (CA10-90), which cause an increase in GIE. However, the 2I-worst case than the CDC case presented longer and late combustion, thereby reducing the effective expansion ratio and increasing the heat transfer (HT) losses, as will be discussed later. The 3I case shows a higher peak in-cylinder temperature than the CDC; however, the HT losses are lower for 3I and 2I-best cases than the CDC case, as will be discussed in the following section. 


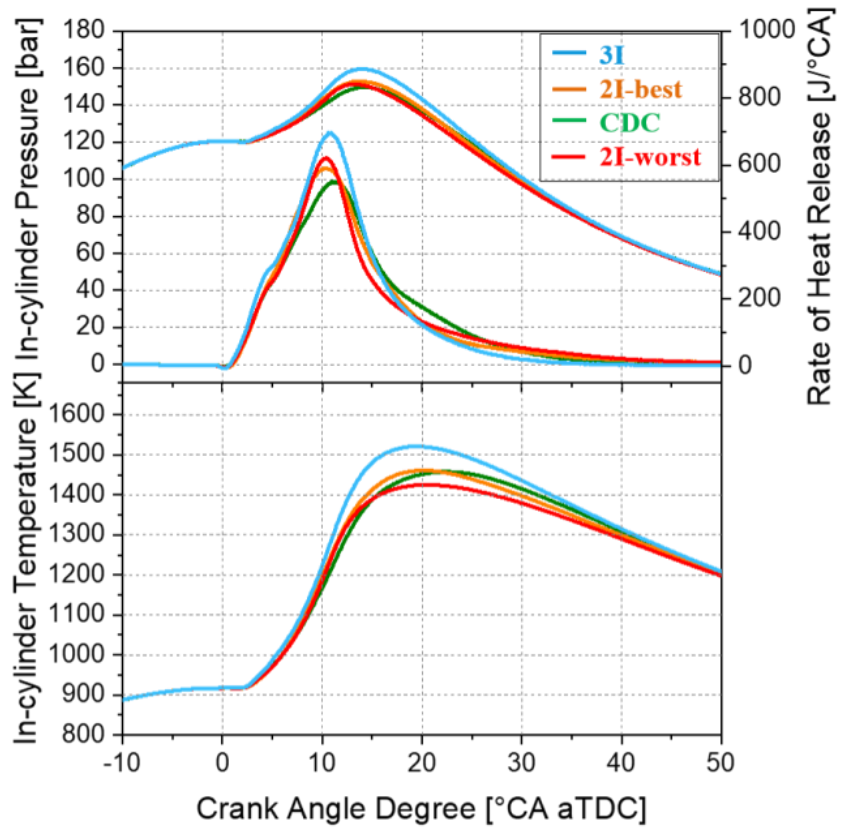

Figure 8. The in-cylinder pressure, rate of heat release (RoHR), and in-cylinder temperature of the combustion chamber for the 3I, 2I-best, CDC, and $2 \mathrm{I}$-worst cases.

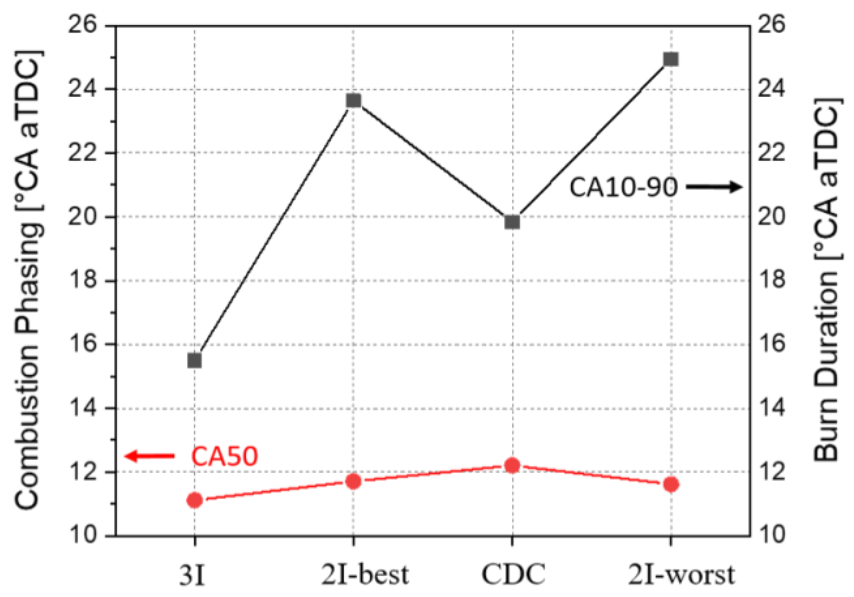

Figure 9. The combustion phasing (CA50) and burn duration (CA10-90) of the combustion cylinder for the 3I, 2I-best, CDC, and 2I-worst cases.

\subsubsection{Energy Distribution and Heat Transfer Analysis}

Figure 10 illustrates the energy balance for the discussed cases, where combustion losses are omitted since the combustion efficiency was higher than 99.7\%. 3I and 2I-best cases have 1.2 and $0.2 \%$-points higher GIE than the CDC case, respectively. Also, these two cases have lower HT losses, and the 2I-best case showed the highest exhaust energy than the CDC case. A $1.3 \%$-points and $2 \%$-points HT losses reduction is obtained by the $3 \mathrm{I}$ and 2I-best cases, respectively, compared with the CDC. Although the indicated work is only higher for the 3I and 2I-best case than the CDC, the combined effect of the lower HT losses and higher exhaust energy makes the multiple injector concept potentially more suitable for the DCEE concept. Figure 10 connected with the previous discussion in Figures 8 and 9 that the 2I-worst presents a late combustion, which increases the burn duration and produces higher HT losses and lower indicated work than the 3I and 2I-best cases.

Figure 11 presents the HT losses from different boundaries, where the piston surface is responsible for more than $50 \%$ of these losses. Although the two-injector cases experience a similar liner and head HT, the total HT reduces as an effect of the reduced piston HT. This directly affects the sideinjectors cases that target the injections towards the center of the combustion chamber instead of the piston surface. Figure 11 also shows the correct spray pattern's importance, where the 2I-best case has the lowest HT losses. Comparing the two-top GIE cases presented in Figure 11, it is seen that the main difference between them is the HT losses by the head and liner. 


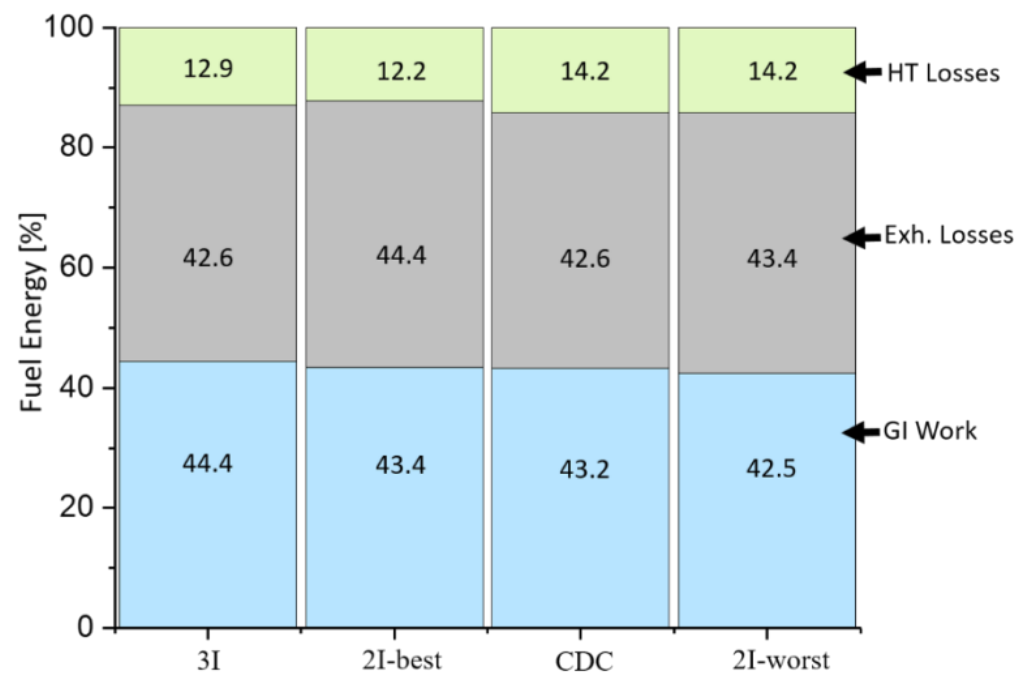

Figure 10. The energy distribution of the combustion cylinder for the 3I, 2I-best, CDC, and 2I-worst cases.

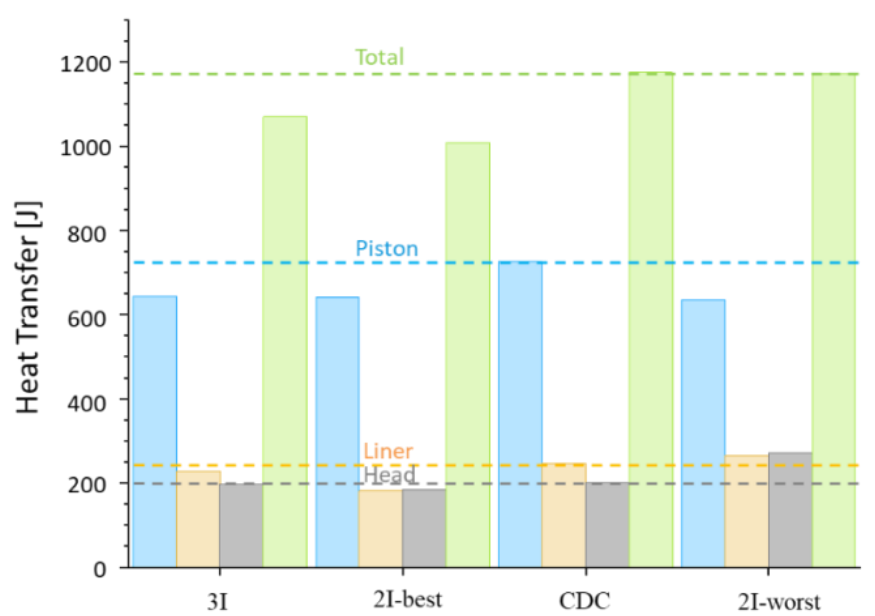

Figure 11. The heat transfer losses of the combustion cylinder for the 3I, 2I-best, CDC, and 2I-worst cases.

Figure 12 shows the near-wall gas temperature distribution at different crank angle locations, to explain the lower 3I and 2I-best HT losses compared to the CDC and 2I-worst cases. The CDC experiences significantly larger high-temperature areas, for each crank angle location, than the 3I -and 2I cases. The side-injections provided a longer injector-wall distance explaining this phenomenon. Figure 13 confirms this observation where the CDC near-piston fluid cells reach a high temperature compared to its multiple-injector counterparts. This occurs despite the early high heat-release from the multiple-injector cases (see Figure 8 and Figure 9). Thus, the multiple-injector concepts combine the two efficiency-enhancing phenomena, fast heat release and low heat losses.

The 3I case interaction between the side and central injections, and the piston bowl, leads to a near-head and near-liner fuel distribution with following high-temperature zones (see Figure 12 at 16 and $20^{\circ} \mathrm{CA}$ aTDC). This possibly explains the higher head -and liner HT losses, compared to the 2I-best case. The 2I-worst case suffers from two major drawbacks: a lower umbrella angle, compared to the 2I-best case; and a shorter distance from outer spray-to-piston, compared to the 2I-best case. These two drawbacks render early high-temperature piston zones (at 5, 10 and $12{ }^{\circ} \mathrm{CA}$ aTDC), compared to the 2I-best case. 


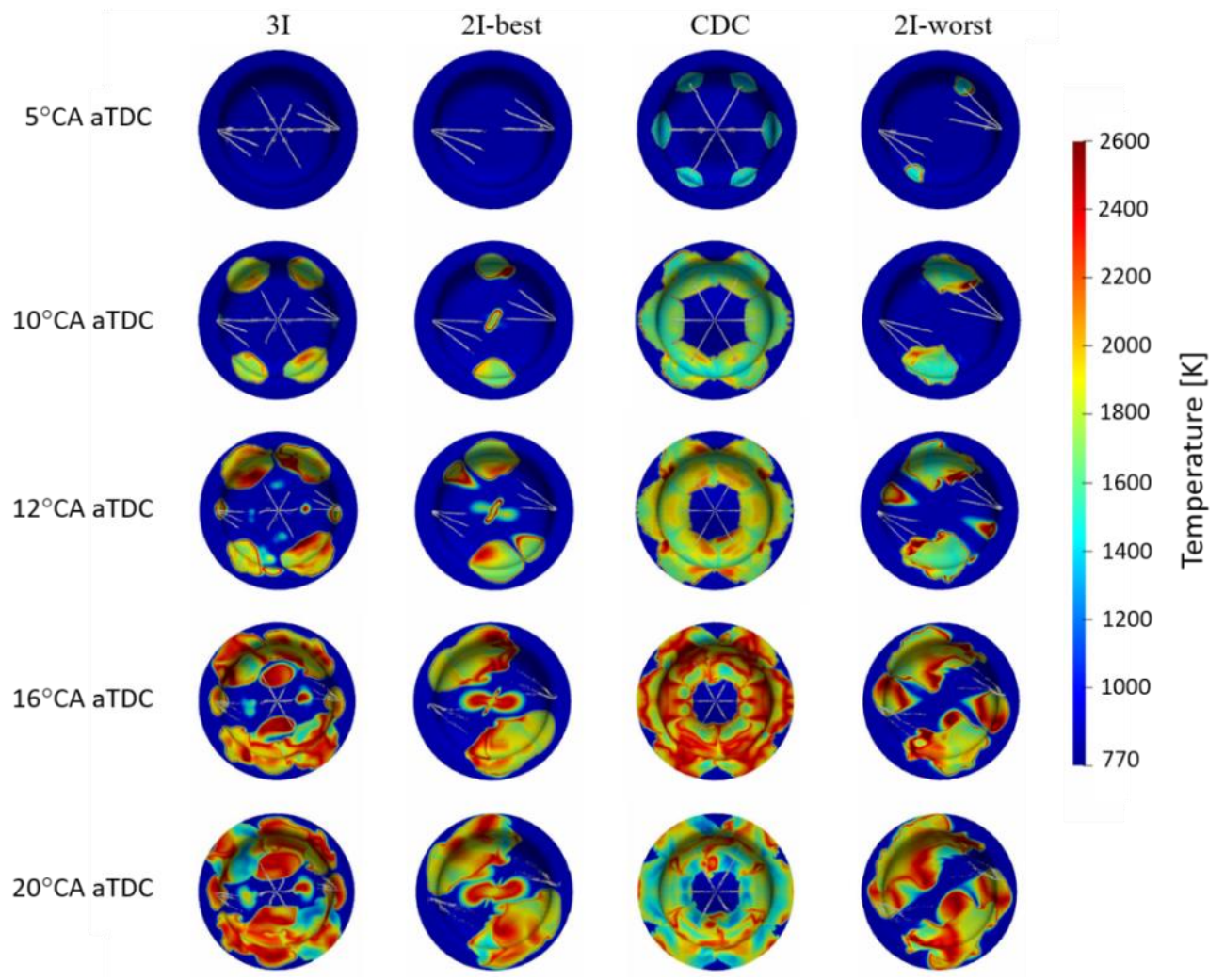

Figure 12. The distribution of near-wall gas temperature of the combustion cylinder for the 3I, 2I-best, CDC, and 2I-worst cases.

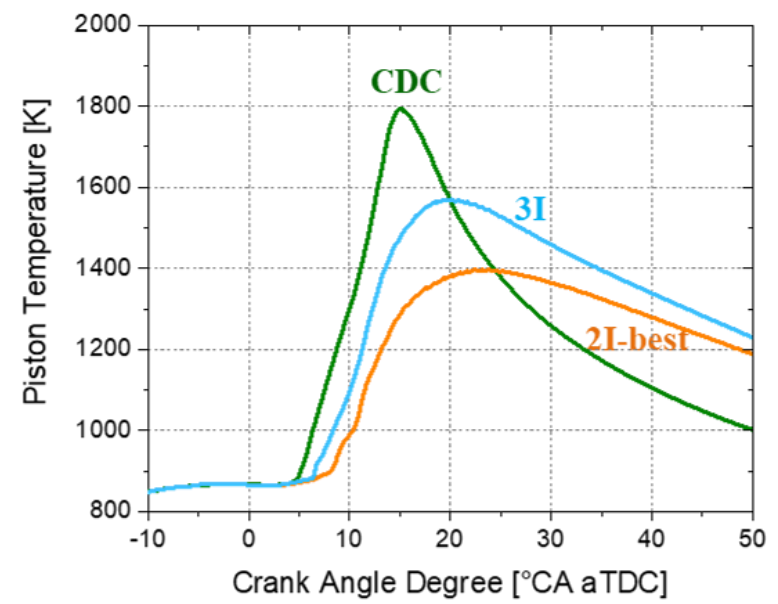

Figure 13. The average temperature of the fluid boundary cells, in the piston vicinity, to illustrate the high CDC peak piston temperature.

\subsection{1-D Analysis of the Double Compression Expansion Engine (DCEE) Concept}

Figure 14 illustrates the in-cylinder pressure and rate of heat release (RoHR) traces for the 3I and 2I-best cases (in the top row), while CDC and 2Iworst cases (in the bottom row), comparing 1-D GT-Power simulations with the CFD results. It is noted that 1-D cylinder pressure analysis during the valve closure period does not allow the modeling of multiple direct fuel injectors. Therefore, the 3I case with six holes for the central injector and three holes each for the side-injectors was assumed to be a single central injector with twelve holes. Similarly, the 2I cases were also considered as a single central injector with six holes. Since all the injectors share the same fuel and injection parameters, therefore assuming multiple injectors as single injectors would not be an issue. This is well reflected in Figure 14, as the 1-D in-cylinder pressure and RoHR traces for all the studied cases match the CFD data closely.

Page 11 of 17 
Figure 15 shows the energy distribution of brake work, friction losses, exhaust losses, and heat transfer losses for the 3I, 2I-best, CDC, and 2I-worst cases of the DCEE concept. The overall brake work was normalized based on the input fuel energy of the combustion cylinder. While the heat transfer and friction losses were calculated using the Woschni equation and linear friction model, respectively, the exhaust losses were estimated using the exhaust flow rate and temperature. From Figure 15, it is seen that 3I case showed higher brake work, followed by 2I-best, CDC, and 2I-worst cases, consistent with the trend of gross indicated work in Figure 10. The three-injectors case resulted in a higher PCP of $\sim 160$ bar compared to PCP of $\sim 150$ bar for the other cases, leading to $0.1 \%$ higher friction losses for the former case. The 2I-best and 2I-worst cases resulted in higher exhaust losses than the 3I and CDC cases. This is primarily due to the extended burn duration, as previously shown in Figure 9. This means the effective expansion ratio of the 2I cases are lower, resulting in lesser heat extraction from the combustion cylinder gases and consequently higher exhaust temperature and exhaust enthalpy, compared to the 3I and CDC cases. For a given case, the heat transfer losses in the combustion cylinder of the DCEE concept were kept consistent as those of the CFD simulations by adjusting the convective heat transfer factor. However, a $2 \%$-points increase in heat transfer losses in Figure 15, compared to Figure 10 represents the losses incurred in the compression and expansion cylinders.
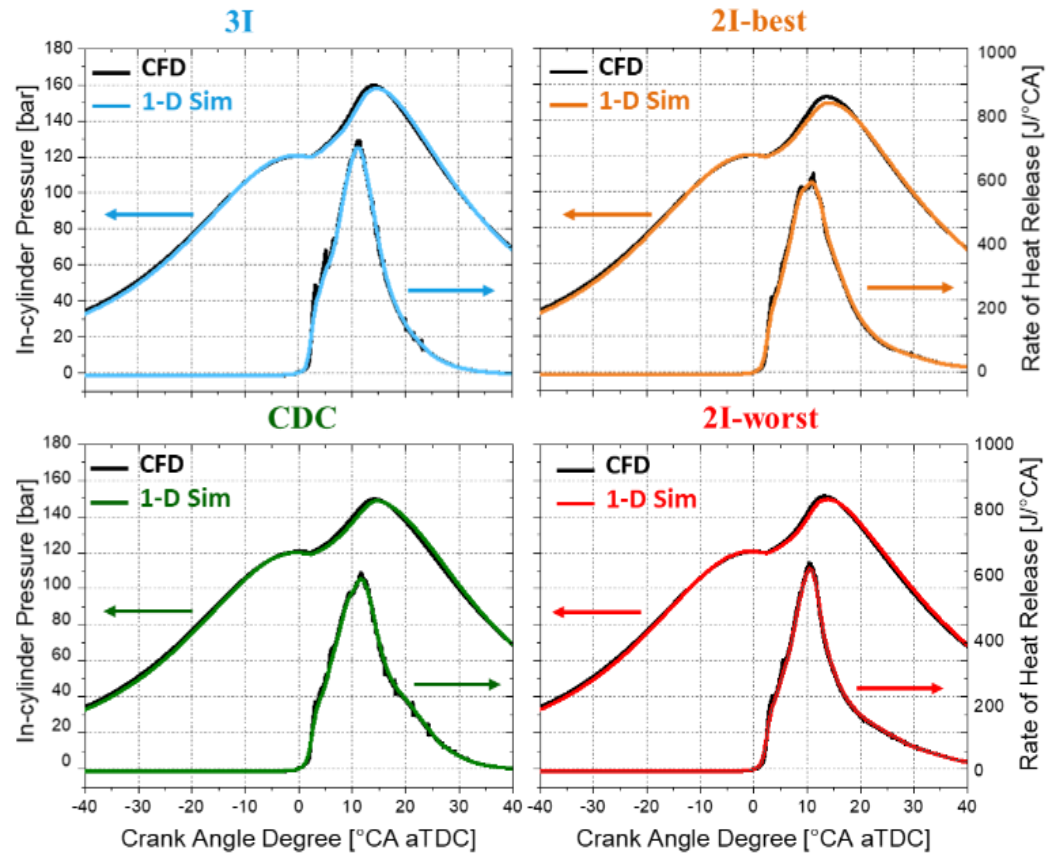

Figure 14. The in-cylinder pressure and rate of heat release (RoHR) traces of the combustion chamber comparing 1-D simulation with the CFD data for the 3I, 2I-best, CDC, and 2I-worst cases.

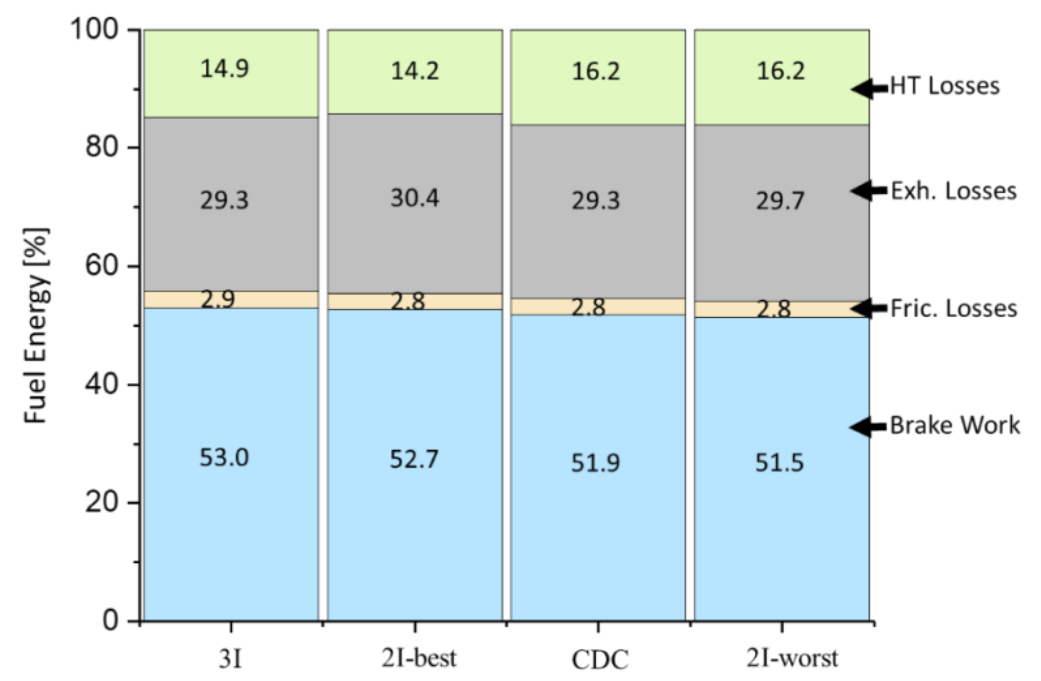

Figure 15. The energy distribution of DCEE concept for the 3I, 2I-best, CDC, and 2I-worst cases.

To further examine how the overall energy flow, as shown in Figure 15, was distributed among the compression, combustion, and expansion cylinder of the DCEE concept using the 3I case, Figure 16(a) was generated. The stroke efficiency and friction losses for each cylinder were normalized according to the combustion cylinder fuel energy. The compression cylinder is based on a two-stroke cycle. The first stroke performs two tasks, i.e., 
the induction of the ambient air from the top dead center (TDC) to bottom dead center (BDC) and the re-expansion after the constant-pressure process to bring the in-cylinder pressure back to the ambient conditions. The second stroke also performs two tasks, i.e., the first-compression of the ambient air from BDC to TDC and the constant-pressure transfer of gases to the low-pressure (LP) tank. This resulted in a net stroke compressor efficiency of $-12.5 \%$.

The combustion cylinder operates on a conventional 4-stroke cycle. The compressed air from the LP tank is inducted into the combustor unit during the third stroke. The compressed air undergoes a second-compression process from BDC to TDC in the fourth stroke. The fuel injection event occurs at the end of the fourth stroke. The high-pressure and temperature gases during the combustion process undergo the first-expansion from TDC to BDC in the fifth stroke, followed by the transfer of exhaust gases to the high-pressure (HP) tank in the sixth stroke. This lead to the net stroke combustor efficiency of $32.0 \%$.
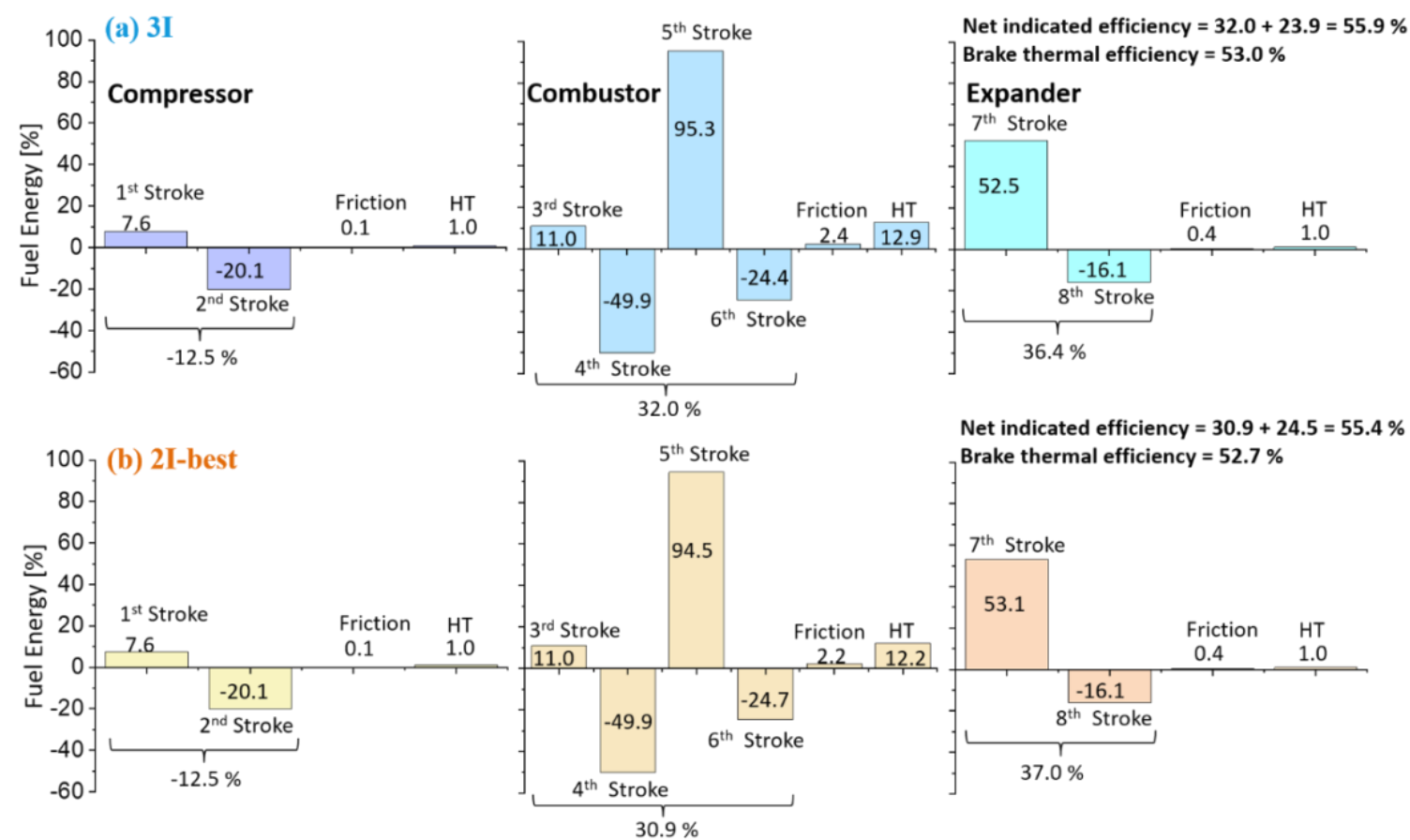

Net indicated efficiency $=\mathbf{3 0 . 9}+\mathbf{2 4 . 5}=\mathbf{5 5 . 4} \%$
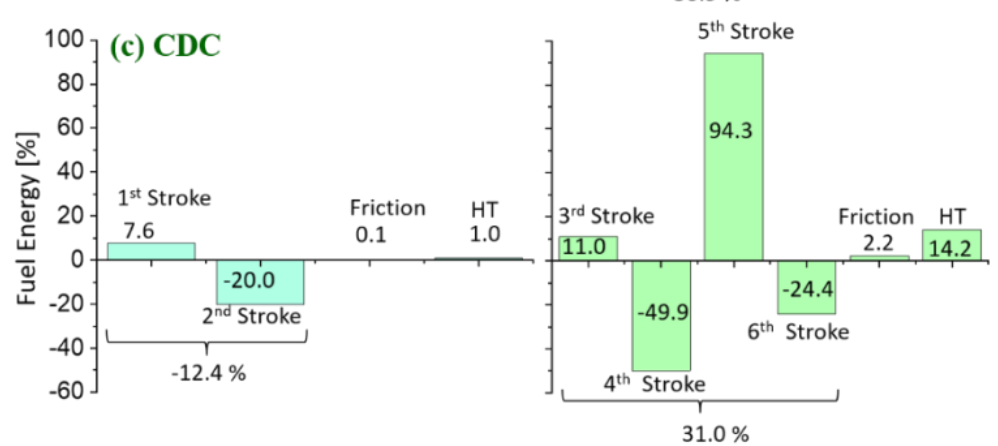

Net indicated efficiency $=31.0+23.6=54.6 \%$

Brake thermal efficiency $=\mathbf{5 2 . 7} \%$
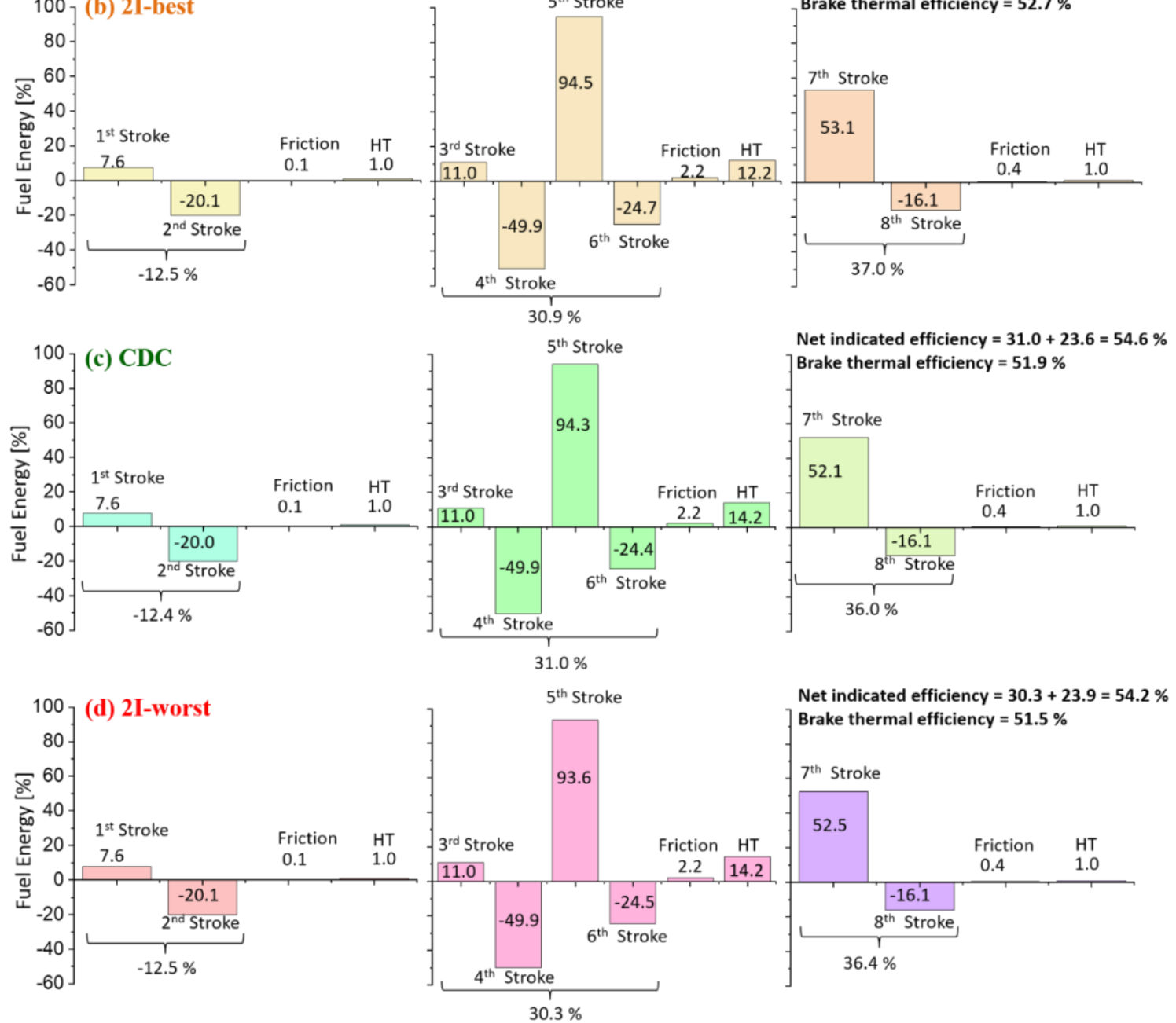

Figure 16. The energy distribution breakdown for the individual cylinders of the DCEE concept for the 3I (a), 2I-best (b), CDC (c), and 2I-worst (d) cases.

Page 13 of 17 
Similar to the compression cylinder, the expansion cylinder is also based on a two-stroke cycle. The seventh stroke conducts two tasks, i.e., the induction of exhaust gases from the HP tank to the compressor unit and the second-expansion till the gases reach the ambient conditions. The eighth stroke also performs two tasks, i.e., the expulsion of the fully expanded gases and re-compression to bring the in-cylinder pressure back to the HP tank's pressure. The expansion cylinder resulted in a net stroke efficiency of $36.4 \%$, which is $4.4 \%$-points higher than the combustion cylinder.

Note from Figure 16(a) that $24.4 \%$ of the exhaust energy from the combustion cylinder resulted in $36.4 \%$ of useful work from the expansion cylinder. The combined net indicated efficiency from the compression-expansion cylinder, i.e., the low-pressure unit is $23.9 \%$, which, when added to the combustion cylinder, i.e., high-pressure unit efficiency of $32.0 \%$, resulted in an overall net indicated efficiency of $55.9 \%$.

As the compression and expansion cylinder operates at much lower peak pressure compared to the combustion cylinder, the friction losses are an order of magnitude lower for the low-pressure unit. Higher heat transfer losses were accounted for the combustion cylinder based on the CFD data, while $1 \%$ of the heat losses were found for both the compression and expansion cylinders.

Figures 16(b), 16(c), and 16(d) shows the energy flow breakdown for the 2I-best, CDC, and 2I-worst cases, respectively. It is seen that the compressor efficiency does not offer a significant variation as the geometrical parameters and intake air temperature and pressure were kept the same for all the cases. The combustion cylinder, $5^{\text {th }}$ and $6^{\text {th }}$ stroke show marked variations in indicated efficiency due to the combustion event. For instance, the $2 \mathrm{I}-$ worst case showed the lowest efficiency due to the cumulative effect of retarded combustion phasing and the longest burn duration. The 2I-worst case showed the highest exhaust losses during the $6^{\text {th }}$ stroke; however, this additional exhaust energy was converted into useful work in the expansion cylinder unit during the $7^{\text {th }}$ stroke. Therefore, this case resulted in the highest expander efficiency of $37.0 \%$, which is $1.0 \%$ and $0.6 \%$-points higher than $\mathrm{CDC}$ and 3I case, respectively. However, the combustion cylinder efficiency was a more dominant factor for the estimation of brake thermal efficiency as the 2I-best case resulted in $0.3 \%$-points overall lower efficiency than the 3I case.

\title{
4. Conclusions
}

Various multiple injector strategies were examined as a means to improve the performance of a single-cylinder heavy-duty Volvo engine and double compression expansion engine (DCEE) concept. 3-D RANS CFD simulations were used to optimize three-injectors and two-injectors cases based on the spray and injection angles and the results were compared with those from a conventional central-mounted single-injector. Subsequently, 1-D simulations were used to further enhance the understanding of energy distribution breakdown for the compression, combustion, and expansion cylinders of the DCEE concept. The major conclusions drawn from this study are shown below:

- The multiple injector cases resulted in a higher peak in-cylinder pressure/temperature and RoHR due to better fuel-air mixing, compared to the single-injector case.

- The three-injectors and an optimized case of two side-injectors resulted in a higher gross indicated efficiency due to earlier combustion phasing and lower heat transfer losses than the baseline case of single-injector. Reduced heat transfer losses for the multiple injectors were attributed to the longer injector-wall distance, resulting in significantly lower high-temperature regions than the single-injector case.

- The cases of 3I and 2I-best resulted in 1.1\%-points (2.1\% increase) and $0.8 \%$-points (1.5\% increase) improvement in brake thermal efficiency compared to the single-injector case. Because of longer burn duration or slow-burning, the 2I-best case also led to the highest exhaust losses. This resulted in the highest conversion of exhaust energy from the combustion cylinder to the useful work extracted from the expansion cylinder, which is $0.7 \%$-points higher than the single-injector case.

\author{
Abbreviations \\ 1-D - One-dimensional \\ 3-D - Three-dimensional \\ ${ }^{\circ} \mathbf{C A}$ - Crank Angle Degree \\ aTDC - After Top-dead Center \\ AC - Alternating Current \\ AMR - Adaptive Mesh Refinement \\ BDC - Bottom Dead Center \\ BTE - Brake Thermal Efficiency \\ CAC - Compressed Air Cooler \\ CDC - Conventional Diesel Combustion \\ CFD - Computational Fluid Dynamics \\ CI - Compression Ignition \\ $\mathrm{CO}_{2}$ - Carbon Dioxide \\ CoV - Coefficient of Variation \\ DCEE - Double Compression Expansion Engine \\ EVO - Exhaust Valve Opening \\ FuelMEP - Fuel Mean Effective Pressure \\ GIE - Gross Indicated Efficiency
}

Page 14 of 17 
HCCI - Homogenous Charge Compression Ignition

HP - High-pressure

HT - Heat-transfer

IMEP - Indicated Mean Effective Pressure

IVC - Inlet Valve Closing

KH-RT - Kelvin-Helmholtz Rayleigh-Taylor

LP - Low-pressure

LTC - Low Temperature Combustion

NO - Nitric Oxide

NO $\mathbf{x}$ - Nitrogen Oxides

PCP - Peak Cylinder Pressure

PPC - Partially Premixed Combustion

PM - Particulate Matter

RANS - Reynold-averaged Navier-Stokes

RCCI - Reactivity Controlled Compression Ignition

RoHR - Rate of Heat Release

RPM - Revolutions Per Minute

TDC - Top Dead Center

TPRF - Toluene Primary Reference Fuels

\section{References}

1. Reitz, R.D., Ogawa, H., Payri, R., Fansler, T., Kokjohn, S., Moriyoshi, Y., Agarwal, A.K., Arcoumanis, D., Assanis, D., Bae, C., Boulouchos, K., Canakci, M., Curran, S., Denbratt, I., Gavaises, M., Guenthner, M., Hasse, C., Huang, Z., Ishiyama, T., Johansson, B., Johnson, T. V., Kalghatgi, G., Koike, M., Kong, S.C., Leipertz, A., Miles, P., Novella, R., Onorati, A., Richter, M., et al., "IJER editorial: The Future of the Internal Combustion Engine," Int. J. Engine Res. 21(1):3-10, 2020, doi:10.1177/1468087419877990.

2. Xu, M., Gui, Y., and Deng, K. yao, "Fuel Injection and EGR Control Strategy on Smooth Switching of CI/HCCI Mode in a Diesel engine," J. Energy Inst. 88(2):157-168, 2015, doi:10.1016/j.joei.2014.06.005.

3. You-cheng, S., Min, X., Yong, G., Yi, C., Lei, S., and Kang-yao, D., "Effects of Injection Pressure, Exhaust Gas Recirculation and Intake Pressure on the Cycle-to-cycle Variations of HCCI Combustion," J. Energy Inst. 89(2):293-301, 2016, doi:10.1016/j.joei.2015.01.017.

4. Vélez Godiño, J.A., Jiménez-Espadafor Aguilar, F.J., and García, M.T., "Simulation of HCCI Combustion in Air-Cooled Off-road Engines Fuelled with Diesel and Biodiesel,” J. Energy Inst. 91(4):549-562, 2018, doi:10.1016/j.joei.2017.04.002.

5. Aydoğan, B., "Experimental Investigation of Tetrahydrofuran Combustion in Homogeneous Charge Compression Ignition (HCCI) Engine: Effects of Excess Air Coefficient, Engine Speed and Inlet Air Temperature,” J. Energy Inst. 93(3):1163-1176, 2020, doi:10.1016/j.joei.2019.10.009.

6. Kavuri, C., Paz, J., and Kokjohn, S.L., "A Comparison of Reactivity Controlled Compression Ignition (RCCI) and Gasoline Compression Ignition (GCI) Strategies at High Load, Low Speed Conditions,” Energy Convers. Manag. 127:324-341, 2016, doi:10.1016/j.enconman.2016.09.026.

7. Goyal, H., Kook, S., and Ikeda, Y., "The Influence of Fuel Ignition Quality and First Injection Proportion on Gasoline Compression Ignition (GCI) Combustion in a Small-bore Engine,” Fuel 235:1207-1215, 2019, doi:10.1016/j.fuel.2018.08.090.

8. Goyal, H. and Kook, S., "Ignition Process of Gasoline Compression Ignition (GCI) Combustion in a Small-bore Optical Engine," Fuel 256:115844, 2019, doi:10.1016/j.fuel.2019.115844.

9. Goyal, H., Zhang, Y., Kook, S., Kim, K.S.., and Kweon, C.-B., "Low- to High-temperature Reaction Transition in a Small-bore Optical Gasoline Compression Ignition (GCI) Engine,” SAE Int. J. Engines 12(5), 2019, doi:10.4271/03-12-05-0031.

10. Liu, H., Tang, Q., Yang, Z., Ran, X., Geng, C., Chen, B., Feng, L., and Yao, M., "A Comparative Study on Partially Premixed Combustion (PPC) and Reactivity Controlled Compression Ignition (RCCI) in an Optical Engine," Proc. Combust. Inst. 37(4):4759-4766, 2019, doi:10.1016/j.proci.2018.06.004.

11. Kokjohn, S., Reitz, R.D., Splitter, D., and Musculus, M., "Investigation of Fuel Reactivity Stratification for Controlling PCI Heat-release Rates Using High-speed Chemiluminescence Imaging and Fuel Tracer Fluorescence," SAE Int. J. Engines 5(2):2012-01-0375, 2012, doi:10.4271/2012-01-0375.

12. Senthil Kumar, M., Arul, K., and Sasikumar, N., "Impact of Oxygen Enrichment on the Engine's Performance, Emission and Combustion Behavior of a Biofuel Based Reactivity Controlled Compression Ignition Engine,” J. Energy Inst. 92(1):51-61, 2019, doi:10.1016/j.joei.2017.12.001.

13. Tang, Q., Liu, H., Ran, X., Li, M., and Yao, M., "Effects of Direct-injection Fuel Types and Proportion on Late-injection Reactivity Controlled Compression Ignition," Combust. Flame 211:445-455, 2020, doi:10.1016/j.combustflame.2019.10.018.

14. Cummins, L., "Diesel's Engine: From Conception to 1918," Carnot Press, 1993.

15. Phillips, F., Gilbert, I., Pirault, J.P., and Megel, M., "Scuderi Split Cycle Research Engine: Overview, Architecture and Operation,” SAE Int. J. Engines 4(1):450-466, 2011, doi:10.4271/2011-01-0403.

16. Dong, G., Morgan, R., and Heikal, M., “A Novel Split Cycle Internal Combustion Engine with Integral Waste Heat Recovery,” Appl.

Page 15 of 17 
Energy 157:744-753, 2015, doi:10.1016/j.apenergy.2015.02.024.

17. Clarke, J.M. and Berlinger, W.G., “A New Compression Ignition Engine Concept for High Power Density,” J. Eng. Gas Turbines Power 121(2):211-217, 1999, doi:10.1115/1.2817107.

18. Clarke, J. and O'Malley, E., “Analytical Comparison of a Turbocharged Conventional Diesel and a Naturally Aspirated Compact Compression Ignition Engine Both Sized for a Highway Truck," SAE paper 2013-01-1736, 2013, doi:10.4271/2013-01-1736.

19. Durrett, R.P. and Gopalakrishnan, V., "Internal Combustion Engine Utilizing Dual Compression and Dual Expansion Processes," US8371256B2, United States, 2009.

20. Meldolesi, R. and Badain, N., "Scuderi Split Cycle Engine: Air Hybrid Vehicle Powertrain Simulation Study," SAE paper 2012-01-1013, 2012, doi:10.4271/2012-01-1013.

21. Finneran, J., Garner, C.P., Bassett, M., and Hall, J., “A Review of Split-cycle Engines,” Int. J. Engine Res., 2018, doi: $10.1177 / 1468087418789528$.

22. Lam, N., Tuner, M., Tunestal, P., Andersson, A., Lundgren, S., and Johansson, B., "Double Compression Expansion Engine Concepts: A Path to High Efficiency," SAE Int. J. Engines 8(4):1562-1578, 2015, doi:10.4271/2015-01-1260.

23. Lam, N., Andersson, A., and Tunestal, P., "Double Compression Expansion Engine Concepts: Efficiency Analysis Over a Load Range," SAE paper 2018-01-0886, 2018, doi:10.4271/2018-01-0886.

24. Lam, N., Tunestal, P., and Andersson, A., "Analyzing Factors Affecting Gross Indicated Efficiency when Inlet Temperature is Changed," SAE paper 2018-01-1780, 2018, doi:10.4271/2018-01-1780.

25. Lam, N., Tunestal, P., and Andersson, A., "Simulation of System Brake Efficiency in a Double Compression-Expansion Engine-Concept (DCEE) Based on Experimental Combustion Data," SAE paper 2019-01-0073, 1-22, 2019, doi:10.4271/2019-01-0073.

26. Bhavani Shankar, V.S., Lam, N., Andersson, A., and Johansson, B., "Optimum Heat Release Rates for a Double Compression Expansion (DCEE) Engine," SAE paper 2017-01-0636, 2017, doi:10.4271/2017-01-0636.

27. Okamoto, T. and Uchida, N., "New Concept for Overcoming the Trade-off Between Thermal Efficiency, Each Loss and Exhaust Emissions in a Heavy Duty Diesel Engine," SAE Int. J. Engines 9(2), 2016, doi:10.4271/2016-01-0729.

28. Uchida, N., Okamoto, T., and Watanabe, H., "A New Concept of Actively Controlled Rate of Diesel Combustion for Improving Brake Thermal Efficiency of Diesel Engines: Part 1-Verification of the Concept," Int. J. Engine Res. 19(4):474-487, 2018, doi:10.1177/1468087417720332.

29. Uchida, N. and Watanabe, H., "A new concept of actively controlled rate of diesel combustion (ACCORDIC): Part II-simultaneous improvements in brake thermal efficiency and heat loss with modified nozzles," Int. J. Engine Res. 20(1):34-45, 2019, doi: $10.1177 / 1468087418820472$.

30. Nyrenstedt, G., Alturkestani, T., Im, H., and Johansson, B., "CFD Study of Heat Transfer Reduction Using Multiple Injectors in a DCEE Concept," SAE paper 2019-01-0070, 2019, doi:10.4271/2019-01-0070.

31. Nyrenstedt, G., Im, H., Andersson, A., and Johansson, B., "Novel Geometry Reaching High Efficiency for Multiple Injector Concepts," SAE paper 2019-01-0246, 2019, doi:10.4271/2019-01-0246.

32. Dyuisenakhmetov, A., Goyal, H., Houidi, M. Ben, Babayev, R., and Badra, J., "Isobaric Combustion at a Low Compression Ratio," SAE paper 2020-01-0797, 2020, doi:10.4271/2020-01-0797.

33. Goyal, H., Dyuisenakhmetov, A., Houidi, M. Ben, Johansson, B., Badra, J., Cenker, E., and Chang, J., "The Effect of Engine Speed, Exhaust Gas Recirculation, and Compression Ratio on Isobaric Combustion,” SAE Int. J. Engines 13(5), 2020, doi:10.4271/03-13-05-0038.

34. Reitz, R.D. and Diwakar, R., "Structure of High-pressure Fuel Sprays," SAE paper 870598, 1987, doi:10.4271/870598.

35. Amsden, A., O’Rourke, P., and Butler, T., "KIVA-II: A Computer Program for Chemically Reactive Flows with Sprays,” 1989, doi: $10.2172 / 6228444$.

36. Sarathy, M., Atef, N., Alfazazi, A., Badra, J., Zhang, Y., Tzanetakis, T., and Pei, Y., "Reduced Gasoline Surrogate (Toluene/n-Heptane/isoOctane) Chemical Kinetic Model for Compression Ignition Simulations," SAE paper 2018-01-0191, 2018, doi:10.4271/2018-01-0191.

Babajimopoulos, A., Assanis, D.N., Flowers, D.L., Aceves, S.M., and Hessel, R.P., "A Fully Coupled Computational Fluid Dynamics and Multi-zone Model with Detailed Chemical Kinetics for the Simulation of Premixed Charge Compression Ignition Engines," Int. J. Engine Res. 6(5):497-512, 2005.

38. Angelberger, C., Poinsot, T., and Delhay, B., "Improving Near-wall Combustion and Wall Heat Transfer Modeling in SI Engine Computations," SAE paper 972881, 1997, doi:https://doi.org/10.4271/972881.

39. Heywood, J.B., "Internal Combustion Engine Fundementals,” ISBN 007028637X, 1988, doi:10987654.

40. Nyrenstedt, G., Ramadan, A. Al, Tang, Q., Badra, J., Cenker, E., Houidi, M. Ben, and Johansson, B., "Isobaric Combustion for High Efficiency in an Optical Diesel Engine," SAE paper 2020-01-0301, 2020, doi:10.4271/2020-01-0301.

41. Nyrenstedt, G., Tang, Q., Sampath, R., Alramadan, A., Houidi, M. Ben, Cenker, E., Magnotti, G., and Johansson, B., “A Comparative Study of Isobaric Combustion and Conventional Diesel Combustion in both All-metal and Optical Engines," Fuel, 2021, In press.

42. Nyrenstedt, G., Houidi, M. Ben, Babayev, R., Im, H., and Johansson, B., "Computational Fluid Dynamics Investigation on Multiple Injector Concepts at Different Swirl Ratios in a Heavy Duty Engine," ASME Internal Combustion Engine Division Fall Technical Conference, 2020, doi:10.1115/ICEF2020-2933.

43. Babayev, R., Nyrenstedt, G., and Johansson, B., "Computational Study of a Multiple Fuel Injector Concept under High-load and High-EGR Conditions,” SAE paper 2020-01-2034, 2020, doi:10.4271/2020-01-2034. 


\section{Contact Information}

\section{Acknowledgments}

\section{Appendix}

Appendix A. Energy Distribution Comparison between Experiment, CFD and GT-Power for the CDC case

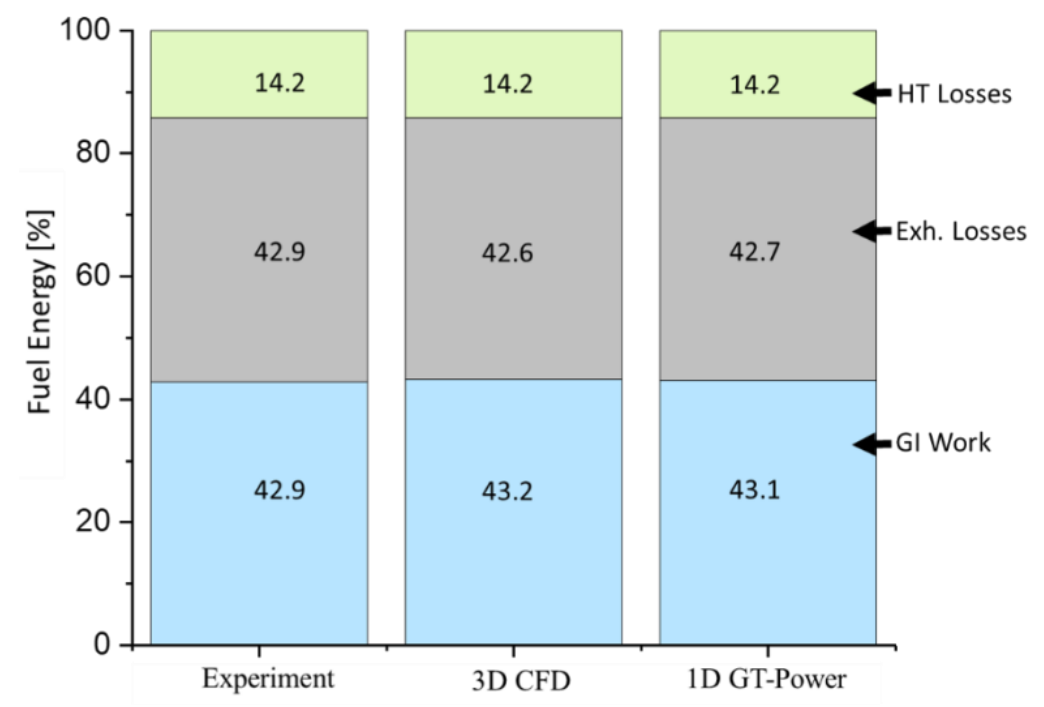

Figure A1. The energy distribution of the combustion cylinder comparing experiment, CFD and GT-Power for the CDC case. 